\title{
A MCDM Approach for Prioritizing Production Lines: A Case Study
}

\author{
Ehsan Pourjavad \\ Department of Industrial Engineering, Najafabad Branch, Islamic Azad University \\ Postal Code: 81966-75954, \#11, Q Block, Hezar Dastgah Residential Complex \\ 22 Bahman St., Malek Shahr St., Isfahan, Iran \\ Tel: 98-311-434-6762 E-mail: Ehsan.pourjavad@Gmail.com
}

Hadi Shirouyehzad (Corresponding author)

Department of Industrial Engineering, Najafabad Branch, Islamic Azad University

Postal Code: 81399-66387, Navid Al., Omid St., Khanehesfahan St., Isfahan, Iran

Tel: 98-331-229-1111Ｅ-mail: Hadi.shirouyehzad@gmail.com

Received: May 18, 2011 Accepted: May 30, $2011 \quad$ Published: October 1, 2011

doi:10.5539/ijbm.v6n10p221 URL: http://dx.doi.org/10.5539/ijbm.v6n10p221

\begin{abstract}
Several methods have been proposed for solving multi-criteria decision making problems (MCDM). A major criticism of MCDM is that different techniques may yield different results when applied to the same problem. A decision maker looks for a solution that is closest to the ideal, in which alternatives are evaluated according to all established criteria. The multiple criteria decision making (MCDM) methods including TOPSIS, ELECTRE and VIKOR are based on an aggregating function representing "closeness to the ideal", which are originated in the compromise programming method. This study provides a comparison analysis of the above-three methods: eight parallel production lines from a factory will be analyzed using these three methods and also aggregate methods will be exploited in order to compare these methods.
\end{abstract}

Keywords: Multi-Criteria Decision Making, TOPSIS(Note 1), ELECTRE(Note 2), VIKOR(Note 3), Aggregate Method

\section{Introduction}

Decision making issue is the most important of all issues that organization managers always deal with, and decision making for various issues is the most important of all challenges for organization managers because progress or breakage of organizations is dependent on decisions that managers make (Huber GP, 1984). Nowadays, the progress of knowledge and technology and increase of competition between organizations have added to the importance of decision making. Often in today's world, decisions are made on the basis of different criteria and new techniques are developed to solve the problem. One state-of-the- art technique that managers use to make decisions is called "multi criteria decision making" or MCDM. MCDM is one of the best techniques to solve problems considering various criteria for decision making (Corner and Kirkwood, 1991).

Multi-Criteria analysis, in many cases called Multi-Criteria Decision-Making (MCDM) or Multi-Criteria Decision Aid methods (MCDA), is a branch of a general class of Operations Research models which deal with the procedure of making decisions in the presence of multiple objectives. These methods, which can handle both quantitative and qualitative criteria, share the common characteristics of oppose among criteria, incommensurable units, and hard in design/selection of alternatives (Pohekar and Ramachandran, 2004).

In general, MCDM methods are separated into Multi-Objective Decision Making (MODM) and Multi-Attribute Decision Making (MADM). The main distinction between the two groups of methods is based on the determination of alternatives. In MODM, also known as multi objective programming or a vector optimization/minimization/maximization problem, the alternatives are not predetermined but instead a set of objective functions is optimized subject to a set of constraints. In MADM, where alternatives are predetermined, a little number of alternatives are to be evaluated against a set of attributes. The best alternative is commonly 
selected by making comparisons between alternatives with respect to each attribute (Pohekar and Ramachandran, 2004).

Following the appearance of multi criteria decision making in science, different algorithms with various methods for solving these problems were brought up. MCDM models include: ELECTRE, TOPSIS, ANP(Note 4), AHP, PROMOTHE(Note 5), VIKOR and so on were brought up, each of which has a different algorithm to solve the problem (Lee and Tu, 2011).

Various articles have been written to compare different multi-criteria decision making models that among them we can mention: Mei-Tai et al. (2007), In the article of "Comparison among three analytical methods for knowledge communities group-decision analysis "3 methods TOPSIS, SAW, ELECTRE were compared that results shown TOPSIS and VIKOR had almost the same success setting priorities by weight. However, VIKOR produced different rankings than those from TOPSIS and SAW, and VIKOR also made it easy to choose appropriate strategies .Both the TOPSIS and VIKOR methods are suitable for assessing similar problems, provide excellent results close to reality, and grant superior analysis.

Opricovic and Tzeng (2004) in the article of "Compromise solution by MCDM methods: A comparative analysis of VIKOR and TOPSIS" that shows their similarity and some differences. A comparative analysis shows that these two methods use different normalizations and that they introduce different aggregating functions for ranking. Opricovic and Tzeng (2007) in the article of "Extended VIKOR method in comparison with outranking methods" 4 methods of VIKOR, TOPSIS, ELECTRE and PROMOTHE are compared in basis of resolve algorithm.

Chatterjee et al. (2009) in the article of "Selection of material using compromise ranking and outranking methods" 2 methods VIKOR and ELECTRE for selecting of material were compared with two examples. Stelios et al. (1998) in the article of "Multi-attribute decision making: A simulation comparison of select methods" 8 methods of multi-criteria decision making in basis of similar results were compared and only showing their similarity.

Yet, MCDM methods with different aspects have been compared mostly on the basis of resolve methods, resolve algorithm, and weighted methods. In this article, however, we compare MCDM methods on the basis of result and using aggregate methods. Any of MCDM methods that have results similar to the ones of aggregate methods is better for comparison and analyzing in critical problems (Momeni, 2007). To put it in anther words, in this article, we ranked production lines of Chadormalu factory on the basis of industry indicators with TOPSIS, ELECTRE I and VIKOR methods. We compared results of MCDM methods with results of aggregate methods and specify the best of MCDM method for comparison in our case study.

The remainder of this paper is organized as follow In Section 2 methods of TOPSIS and VIKOR and ELECTRE I and Aggregate method are reviewed. Methodology for comparison MCDM methods are introduced in Section 3. In Section 4 illustrates a case study for ranking production lines to comparison proposed methods. Discussion is presented in Section 5. Finally, we provide conclusions and remarks in last section.

\section{MCDM methods}

\subsection{TOPSIS}

TOPSIS (technique for order preference by similarity to an ideal solution) method is demonstrated by Chen and Hwang (1992). The basic principle is that the chosen alternative must have the shortest distance from the ideal solution and the farthest distance from the negative-ideal solution.

The TOPSIS procedure consists of the following steps:

(1) Compute the normalized decision matrix. The normalized value $\mathrm{r}_{\mathrm{ij}}$ is calculated as:

$$
\eta_{p}=A_{t} f \sqrt{E_{j=1}^{l} f_{l}^{2}} \quad \mathrm{j}=1, \ldots \ldots \mathrm{J} ; \mathrm{i}=1, \ldots \ldots \mathrm{n}
$$

(2) Calculate the weighted normalized decision matrix. The weighted normalized value $v_{i j}$ is calculated as:

$\mathrm{V}_{\mathrm{ij}}=\mathrm{w}_{\mathrm{i}} \mathrm{r}_{\mathrm{ij}}, \quad \mathrm{j}=1, \ldots \ldots \ldots \mathrm{J} ; \quad \mathrm{i}=1, \ldots \ldots, \mathrm{n}$

Where $\mathrm{w}_{\mathrm{i}}$ is the weight of the $\mathrm{i}_{\text {th }}$ attribute or criterion, and $\sum_{\mathrm{L}} \mathrm{w}_{\mathrm{l}}=1$

(3) Determine the ideal and negative-ideal solution.

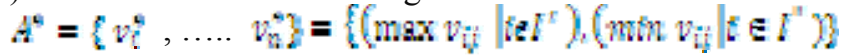

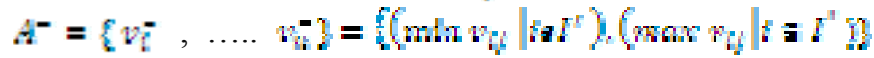

Where $I^{\prime}$ is associated with advantage criteria, and $I^{\prime \prime}$ is associated with cost criteria. 
(4) Calculate the separation measures, using the n-dimensional Euclidean distance. The separation of each alternative from the ideal solution is given as:

$$
D_{j}^{5}=\sqrt{2 i=1\left(v_{t}-v_{i}^{4}\right)}, \quad \mathrm{j}=1, \ldots \ldots . \mathrm{J} .
$$

Similarly, the separation from the negative-ideal solution is given as:

$$
D_{j}^{-}=\sqrt{2 \ln _{1}\left(v_{t}-v_{t}^{-}\right)^{2}} \quad \mathrm{j}=1, \ldots \ldots . . . \mathrm{J} \text {. }
$$

(5) Calculate the relative closeness to the ideal solution. The relative closeness of the alternative $a_{j}$ with respect to $A^{*}$ is defined as:

$$
C_{j}^{\mathrm{s}}=D_{j}^{-} /\left(D_{j}^{\mathrm{s}}+D_{j}^{-}\right), \quad \mathrm{j}=1, \ldots \ldots \mathrm{J} .
$$

(6) Rank the preference order (Wu et al, 2010).

\subsection{ELECTRE I}

The ELECTRE (ELimination and Et Choice Translating REality) method, improved by Roy and Vincke (1981), is based on multi-attribute utility theory (MAUT) with the intention to improve productivity without affecting the outcome while considering less information (Cho KT, 2003). It is a procedure that sequentially decreases the number of alternatives the decision maker is faced within a set of non-dominated alternatives. The concept of an outranking relation $\mathrm{S}$ is introduced as a binary relation explained on the set of alternatives A. Given the alternatives $A_{j}$ and $A_{k}, A_{j}$ outranks $A_{j}$ or $A_{j} S_{j}$, if given all that is known about the two alternatives, there are enough causes to decide that $A_{j}$ is at least as good as $A_{k}$. The goal of this outranking method is to determine all alternatives that dominate other alternatives while they cannot be dominated by any other alternative. To determine the best alternative, the ELECTRE I method also requires the knowledge of the weights of all the criteria. Each criterion $C_{i} \in C$ is assigned a subjective weight, $w_{i}$ (the sum of the weights of all criteria equals to one), and every pair of the alternatives $A_{j}$ and $A_{k}$ is assigned a concordance index, $c(j, k)$ given as below:

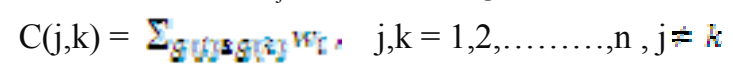

Where $g_{i}(j)$ and $g_{i}(k)$ are the normalized measures of performance of $j$ th and kth alternative, respectively, with respect to ith criterion in the decision matrix. Thus, for an ordered pair of alternatives $\left(A_{j}, A_{k}\right)$, the concordance index $c(j, k)$ is the sum of all the weights for those criteria where the performance score of $A_{j}$ is at least as that of $A_{k}$. Obviously, the concordance index lies between 0 and 1 . A discordance index, $\mathrm{d}(\mathrm{j}, \mathrm{k})$ is also calculated as given below:

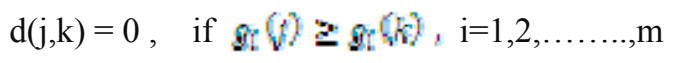

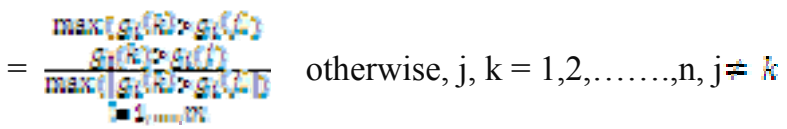

Once these two indices are estimated, an outranking relation $\mathrm{S}$ can be explained as:

$$
\mathrm{A}_{\mathrm{j}} \mathrm{SA}_{\mathrm{k}} \text { if and only if } \mathrm{c}(\mathrm{j}, \mathrm{k}) \geq \varepsilon \text { and } \mathrm{d}(\mathrm{j}, \mathrm{k}) \leq \hat{\lambda}
$$

Where $\hat{c}$ and $d$ are the threshold values as set by the decision maker. If the threshold values are high, it will be more hard to pass the tests (normally $\hat{c}=0.7$ and $\hat{d}=0.3$ (Milani et al., 2006). For an outranking relation to be judged as true, both the concordance and discordance indices should not violate their corresponding threshold values. When these two tests are performed for all the pairs of alternatives, the preferred alternatives are those which outrank more than being outranked. The steps for implementing the ELECTRE1 method are described as below (Kaya and Kahraman, 2011):

Step 1: Obtain the normalized values of all the criteria.

Step 2: Construct the outranking relations by following the concordance and discordance explanations, and develop a graph representing the domination relations among the alternatives. In this graph, if alternative $\mathrm{A}_{j}$ outranks alternative $A_{k}$, then a directed arc exists from $A_{j}$ to $A_{k}$.

Step 3: Acquire a minimum dominating subset by using the minimum concordance and maximum discordance indices.

Step 4: If the subset has a single element or is small enough to apply value judgment, select the last decision. Otherwise, steps $2-4$ are repeated until a single element or small subset exists.

Step 5: If a full ranking of the alternatives is required, apply an expansion of the ELECTRE, i.e. ELECTRE II method. Calculate another two indices as follows (Hatami, Tavana, 2011): 


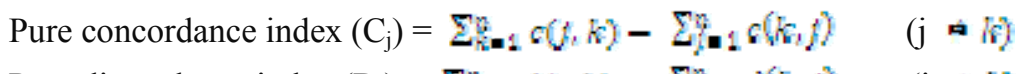

Pure discordance index $\left(D_{\mathrm{j}}\right)=\sum_{\mathrm{n}} \mathrm{d} d(\mathrm{k}, \mathrm{k})-\sum_{-1} d(k, p) \quad(\mathrm{j}=k)$

(a) Once these two indices are estimated, acquire two rankings on the basis of these indices.

(b) Determine an average ranking from the two rankings as obtained in step 5(a).

(c) Select that alternative which has the best average rank.

\subsection{VIKOR}

The VIKOR method was presented as one applicable technique to be implemented within MCDM problem and it was developed as a multi attribute decision making method to solve a discrete decision making problem with non-commensurable (different units) and opposing criteria (Opricovic, Tzeng, 2004). This method focuses on ranking and selecting from a set of alternatives, and determines compromise solution for a problem with opposing criteria, which can help the decision makers to reach a finish solution. The multi-criteria measure for compromise ranking is developed from the $\mathrm{L}_{\mathrm{p}}$-metric used as an aggregating function in a compromise programming method (P.L. Yu, 1973).

Assuming that each alternative is evaluated according to each criterion function, the compromise ranking could be performed by comparing the measure of closeness to the ideal alternative. The different $m$ alternatives are denoted as $A_{1}, A_{2}, \ldots, A_{m}$. For alternative $A_{i}$, the rating of the jth aspect is denoted by $f_{i j} . F_{i j}$ is the value of $j$ th criterion function for the alternative $A_{i} ; n$ is the number of criteria. Development of the VIKOR method is started with the following form of $\mathrm{L}_{\mathrm{p}}$-metric:

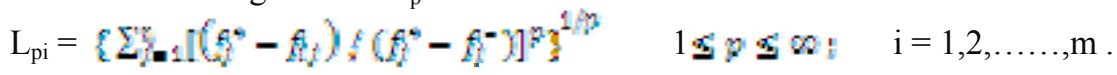

In the VIKOR method $\mathrm{L}_{1, \mathrm{i}}\left(\right.$ as $\mathrm{S}_{\mathrm{i}}$ ) and $\mathrm{L}_{\infty, 1}$ (as $\mathrm{R}_{\mathrm{i}}$ ) are used to formulate ranking measure. The answer obtained by $\min \mathrm{S}_{\mathrm{i}}$ is with a maximum group utility ("majority" rule), and the answer obtained by $\min \mathrm{R}_{\mathrm{i}}$ is with a minimum individual regret of the "opponent".

The compromise ranking algorithm of the VIKOR method has the following steps:

(a) Determine the best $f_{j}^{*}$ and the worst $f_{j}^{-}$values of all criterion functions $\mathrm{j}=1,2, \ldots, \mathrm{n}$. If the jth function represents a profit then:

$$
f^{\prime \prime}=\max f \cdot f^{-}=\min f
$$

(b) Compute the values $S_{i}$ and $R_{i} ; i=1,2, \ldots, m$, by these relations:

$$
\begin{aligned}
\mathrm{S}_{\mathrm{i}} & =\sum_{j}-w_{j}\left(f_{j}^{s}-f_{j}\right) \xi\left(f_{j}^{*}-f_{j}^{-}\right) \\
\mathrm{R}_{\mathrm{i}} & =\max \mathrm{w}_{\mathrm{j}}\left(f_{j}-f_{j}\right) \xi\left(f_{j}^{*}-f_{\mathrm{j}}^{*}\right)
\end{aligned}
$$

Where $\mathrm{w}_{\mathrm{j}}$ are the weights of criteria, expressing their relative importance.

(c) Compute the values $\mathrm{Q}_{\mathrm{i}} ; \mathrm{i}=1,2, \ldots, \mathrm{m}$, by the following relation:

$$
\mathrm{Q}_{\mathrm{i}}=\mathrm{V}\left(S_{\mathrm{i}}-S^{2}\right) /\left(S^{-}-S^{\circ}\right)+(1-\mathrm{V})\left(R_{\mathrm{i}}-R^{2}\right) /\left(R^{-}-R^{*}\right)
$$

Where

$5^{*}=\min \mathrm{S}_{\mathrm{i}}, \quad S^{-}=\max \mathrm{S}_{\mathrm{i}}$

$R^{*}=\min \mathrm{R}_{\mathrm{i}}, \quad R^{-}=\max \mathrm{R}_{\mathrm{i}}$

$\mathrm{v}$ is introduced as weight of the strategy of "the majority of criteria" (or "the maximum group utility"), here suppose that $\mathrm{v}=0.5$.

(d) Rank the alternatives, sorting by the values $\mathrm{S}, \mathrm{R}$ and $\mathrm{Q}$ in decreasing order. The results are three ranking lists.

(e) Propose as a compromise solution the alternative $A^{r}$, which is ranked the best by the measure Q (Minimum) if the following two conditions are satisfied:

C1. Acceptable advantage:

$$
Q\left(A^{2}\right)-Q\left(A^{2}\right) \geq D Q
$$

Where $A^{n}$ is the alternative with second position in the ranking list by Q; DQ $=1 /(\mathrm{m}-1) ; \mathrm{m}$ is the number of alternatives.

C2. Acceptable stability in decision making:

Alternative $A^{x}$ have to also be the best ranked by $\mathrm{S}$ or/and $\mathrm{R}$. This compromise solution is stable within a decision making process, which could be "voting by majority rule" (when $v>0.5$ is needed), or "by consensus" 
$\mathrm{v} \approx 0.5$, or "with veto" $(\mathrm{v}<0.5)$. Here, $\mathrm{v}$ is the weight of the decision making strategy "the majority of criteria" (or "the maximum group utility").

If one of the conditions is not satisfied, then a set of compromise solutions is proposed, which consists of:

Alternatives $A^{r}$ and if $A^{\prime \prime}$ only condition $\mathrm{C} 2$ is not satisfied, or

Alternatives $A^{r}, A^{\prime}, \ldots, A^{N}$ if condition $\mathrm{C} 1$ is not satisfied; $\mathrm{A}^{(\mathrm{M})}$ is resolved by the relation $\mathrm{Q}\left(\mathrm{A}^{(\mathrm{M})}\right)-\mathrm{Q}\left(A^{\mathrm{I}}\right)<\mathrm{DQ}$ for maximum $\mathrm{M}$ (the positions of these alternatives are "in closeness").

The best alternative, ranked by $\mathrm{Q}$, is the one with the minimum value of $\mathrm{Q}$. The principal ranking result is the compromise ranking list of alternatives, and the compromise solution with the "advantage rate". VIKOR is an effective tool in multi-criteria decision making, particularly in a situation where the decision maker is not able, or does not know to express his/her preference at the beginning of system design. The obtained compromise solution could be accepted by the decision makers because it provides a maximum "group utility" (represented by min S) of the "majority", and a minimum of the "individual regret" (represented by min R) of the "opponent". The compromise solutions could be the basis for negotiations, involving the decision maker's preference by criteria weights (Sayadi et al., 2009).

\subsection{Aggregate Methods}

It is a method which is used to compare MCDM methods. It has 4 stages (Wang et al., 2005):

\section{A. Rank Average Method}

This method ranks alternatives on the basis of average of calculated ranks from different MCDM methods.

B. Borda Method

Each MCDM method ranks all of the alternatives. If there are $k$ alternatives, each alternative receives $k$ points for first choice, $k-1$ points for second choice, and so on. The alternative with the most points is declared the winner (Anisseh et al., 2009).

\section{Copeland Method}

This method starts with the end of Borda method. It calculates numbers of losses for all of the alternatives. Subtracting numbers of loses from numbers of wins, it determines the prominence of any alternatives.

\section{Aggregate Stage}

In this stage, with considering rankings strategies (rank average, Borda and Copeland method), and through creating one poset (Note 6), it will arrive to "consensus".

\section{Methodology}

Organizations Managers have always faced with problems in their organizations when analyzing and ranking; and have been searching for methods to analyze correctly among organization units so that they can do a comprehensive and correct comparison according to organizational indexes. This problem, however, was eliminated through the advent of multi criteria decision making. Industry was not an exception either and nowadays industry managers have to deal with different criteria for decision making and need to take these criteria into account if they want to make a good decision.

One of the techniques that managers use nowadays for decision making is called "multi criteria decision making" or MCDM. MCDM is one of the best techniques to solve problems because it considers various criteria for decision making (Corner and Kirkwood, 1991).

But there has emerged another issue with the development of MCDM methods and that was the choice of one method among existing methods for comparison. MCDM methods have different algorithms to resolve problems, for this purpose, in order to resolve critical problems with multi-criteria decision making methods, different answers may arise using each of these methods. Because any one of MCDM methods may give a different answer and it puts the decision-maker in a dilemma that which of these methods gives a correct and real answer.

Decision makers are not limited to one method of MCDM in critical methods because possible various MCDM methods attain to different results. In order to get over this problem, various methods called aggregate methods have been introduced. These methods are called: rank average method, borda method and Copeland method (M. Momeni, 2007).

At this point, we compare 3 methods of MCDM methods in this article to see which one of these methods gives a more suitable answer. ELECTRE I, TOPSIS, VIKOR are the methods which are compared in this article .These methods were used to highlight our innovative idea, academic analysis, and practical appliance value. For this comparison, we evaluated eight parallel production lines according to 14 different criteria in an 
industrial unit and ranked them with these 3 methods. We rank production lines with aggregate methods (rank average, borda, copeland method, and aggregate stage) to determine the accuracy of these methods.

\subsection{Indicators}

Parallel production lines in basis of industry indicators have been ranked. There are three aspects in industry: maintenance and repair, quality, and production. Firstly, critical indicators for a company should be determined. Critical indicators in our industry are as followed:

\section{Maintenance Indicators}

$\checkmark$ MTBF: Mean time between failures (MTBF) is the predicted elapsed time between inherent failures of a system during operation. MTBF can be calculated as the arithmetic mean (average) time between failures of a system (Çekyay, Özekici, 2010).

$\checkmark$ MTTR: Mean time to repair is a basic measure of the maintainability of repairable items. It represents the average time required to repair a failed component or device (Qingfeng et al, 2011).

$\checkmark$ Stoppage Numbers

$\checkmark \quad$ Stoppage Times

Product Indicators

$\checkmark$ Product: quantities of iron concentrate that produce with any line

$\checkmark \quad$ Feed: quantities of iron stone that feed to lines

$\checkmark \quad$ Water Consumption: quantities of water consume with any lines for produce

$\checkmark$ Power Consumption: quantities of electricity consume with any lines for produce

$\checkmark$ Grinding Media: quantities of ball consume for grinding iron stone in lines

$\checkmark$ Recovery: (product/feed)

Quality Indicators

$\checkmark \mathrm{Fe} \%$ : this indicator is grade of iron that is relevant to iron concentrate produced.

$\checkmark \quad \mathrm{P} \%$ : this indicator is grade of phosphor that is relevant to iron concentrate produced.

$\checkmark \quad$ Feo \%: this indicator is oxide of iron that is relevant to iron concentrate produced.

$\checkmark \quad$ Moisture \%: this indicator show moisture of iron concentrate produced.

\subsection{Proposed Method}

i. $\quad$ Displayed method in this article to compare MCDM methods are as followed:

Calculating amounts of critical indicators for production lines: firstly, the indicators and their types that are critical for our industry are determined (positive or negative).

ii. Determining weights between indicators: We need to weigh indicators for comparison these lines with these methods. Then using AHP, we calculate the among criteria weight. To do that, we gave questioners to product, maintenance and repair experts and then with the aid of group AHP we calculate the among criteria weight. To calculate the among criteria weight, we use AHP method, because it calculates more reasonable index weights, compared to entropy methods because it is based on decision makers viewpoints (and not decision making matrix).

iii. Ranking production lines with MCDM methods: we rank production lines with TOPSIS method refer to (2.1) and ELECTRE method refer to (2.2) and VIKOR method refer to (2.3).

iv. Ranking production lines with aggregate method: in this stage we ranking production lines with aggregate method, refer to (4.2).

v. Discussion and deduction from answers: we offer to resolve critical problems using various MCDM methods and find the best method that gives us the correct answer. When problems are resolved with various methods different statuses occur. If it was similar results of all methods, it means that results of all methods are correct and all of methods are suitable for ranking and comparison.

But if results of MCDM methods are dissimilar with one another, comparison gets difficult. Exploiting aggregate methods is the best solution in order to determine a suitable method in this situation. To this point, 
results of these methods are compared with the ones of aggregate methods, any of MCDM methods that have similar result with aggregate is optimum method.

\section{Case Study}

To compare MCDM methods, we ranked parallel production lines in an industry-mining unit in basis of industry indicators and compared the results of each method with one another. Chadormalu industry unit produces iron concentrate and is located 180 kilometers away from Yazd. Firstly, some criteria to compare production lines were chosen. Then, the criteria used in that industry were divided into 3 parts: quality, production, maintenance and repair. Next, the values of all the lines for one working year were measured and the nature of these indicators in basis of positive or negative was determined, the result of which is shown in table 1.

\section{Finding and Discussion}

The weights of criteria with AHP method were calculated. Results are shown in table 2.Then we ranked production lines with three methods of multi-criteria decision making: TOPSIS, VIKOR, and ELECTRE1, Results are shown in table 3. To compare these three methods, we ranked production lines with aggregate methods (rank average method, Borda method, Copeland method, aggregate stage) the result of which is shown in table 4.

Taking one criterion into account in decision making is called one criterion decision making which is not difficult to solve. But when we want to decide with multiple criteria, it would be difficult because all of the criteria should be considered. Mostly managers of organizations face with decisions that should be made with multiple criteria and decisions made by them set the future policies and strategies of the organization. As a result, one incorrect decision will be detrimental to the organization. Particularly when these decisions include such items as: setting the provider, setting the production methods, setting the products, and etc.

To this point, one critical challenge for managers is correct decision makings using methods that yield realistic results. Many different multi-criteria decision making methods have already been introduced to resolve problems of this kind. In this article, we compared 3 methods of MCDM. We ranked parallel production lines of Chadormalu industry considering 14 criteria with all these methods. Results are shown in table3. Each method produced a different ranking.

We ranked production lines with aggregate methods (rank average, borda, copeland method, aggregate stage) to determine the most accurate of these methods (table 4). Results of MCDM methods are not similar to the result of aggregate method and the only method with fairly similar results to aggregate method was TOPSIS method. Lines of 1, 6, and 4 are similar to both TOPSIS and aggregate in ranking, but it cannot say results of two methods are similar.

We cannot say in our case study, which of 3 methods TOPSIS, VIKOR and ELECTRE I gives correct answer. In this article, results of MCDM methods were not similar to result of aggregate method, hence we chose the results of aggregate method as the best result.

\section{Conclusion}

In this article, we compared three methods of multi-criteria decision makings called TOPSIS, ELECTRE I, and VIKOR through analyzing parallel production lines, in order to understand which of these methods yields optimum result. We also compared the results of these methods with aggregate methods. These methods did not produce similar result to aggregate methods; hence none of these methods was optimum for ranking. In this article, we considered aggregate method as the optimum method for ranking. The results of multi-criteria decision making methods in our case study are not similar, but it may make similar results in other cases. In this article, we considered aggregate methods to compare results of MCDM methods but we commit to compare MCDM methods with other methodologies in next research. The compromise ranking and outranking methods can also be used for any type of decision making problem involving any number of quantitative and qualitative criteria and any number of alternatives. Also, aggregate method can be used to compare other different MCDM methods.

Due to the variety of MCDM methods, managers have faced with the problem of selecting the best method for decision making. This paper can help managers to compare MCDM method and select the most suitable one. In this paper, three methods were just analyzed. It is suggested that further researches consider other MCDM methods and analyse them comparatively.

\section{References}

Anisseh, M., Rosnah, Y., \& Shakarami, A. (2009). Aggregating group MCDM problems using a fuzzy Delphi model for personnel performance appraisal. Scientific Research and Essay, 4 (5), 381-391. 
Chatterjee, P., Athawale, V.M., \& Chakraborty, S. (2009). Selection of materials using compromise ranking and outranking methods. Materials and Design, 30, 4043-4053. http://dx.doi.org/10.1016/j.matdes.2009.05.016

Chen, S.J., \& Hwang, C.L. (1992). Fuzzy Multiple Attribute Decision Making: methods and Applications. Springer-Verlag, Berlin.

Cho, KT. (2003). Multi-criteria decision methods: an attempt to evaluate and unify. Mathematical and Computer Modelling, 37, 1099-119. http://dx.doi.org/10.1016/S0895-7177(03)00122-5.

Corner, JL. Kirkwood, CW. (1991). Decision Analysis Applications in the Operations Research Literature. Operation Research, 39 (2), 206-19.

Çekyay, B., \& Özekici, S. (2010). Mean time to failure and availability of semi-Markov missions with maximal repair. European Journal of Operational Research, 207(3), 1442-1454. http://dx.doi.org/10.1016/j.ejor.2010.07.019

Hatami, A., \& Tavana, M. (2011). An extension of the ELECTRE I method for group decision-making under a fuzzy environment. Omega, 39(4), 373-386. http://dx.doi.org/10.1016/j.omega.2010.09.001

Huber, GP. (1984). Issues in the Design of Group Decision Support Systems Management Information. Systems Quarterly. 8, 195-204.

Kaya T, \& Kahraman, C. (2011). An integrated fuzzy AHP-ELECTRE methodology for environmental impact assessment. Expert Systems with Applications, 38(7), 8553-8562. http://dx.doi.org/10.1016/j.eswa.2011.01.057

Lee, W.S., \& Tu, W.S. (2011). Combined MCDM techniques for exploring company value based on Modigliani-Miller theorem. Expert Systems with Applications, 38 (7), 8037-8044. http://dx.doi.org/10.1016/j.eswa.2010.12.138

Mei-Tai, C. Joseph, S., Gwo-Hshiung, T., \& Rajiv K. (2007). Comparison among three analytical methods for knowledge communities group-decision analysis. Expert Systems with Applications, 33, 1011-1024. http://dx.doi.org/10.1016/j.eswa.2006.08.026

Milani, AS., Shanian, A., \& El-Lahham, C. (2006). Using different ELECTRE methods in strategic planning in the presence of human behavioral resistance. Journal Application Mathematics Decision Sciences, Article ID 10936.1-19

Momeni, M. (2007). New topics in operations research. (2 $\mathrm{rd}$ ed.). Tehran, university of tehran Issuance.

Opricovic, S., \& Tzeng, G.H. (2004). Compromise solution by MCDM methods: A comparative analysis of VIKOR and TOPSIS. European Journal of Operational Research, 156, 445-455. http://dx.doi.org/10.1016/S0377-2217(03)00020-1

Opricovic, S., \& Tzeng, G.H. (2007). Extended VIKOR method in comparison with outranking methods. European Journal of Operational Research, 178, 514-529. http://dx.doi.org/10.1016/j.ejor.2006.01.020

Pohekar, SD \& Ramachandran, M. (2004). Application of multi-criteria decision making to sustainable energy planning A review. Renew Sustain Energy, 8, 365-8. http://dx.doi.org/10.1016/j.rser.2003.12.007

P.L. Yu. (1973). A class of solutions for group decision problems. Management Science, 19 (8), 936-946.

Qingfeng, W. Wenbin, L. Xin, Z. Jianfeng, Y., \& Qingbin, Y. (2011). Development and application of equipment maintenance and safety integrity management system. Journal of Loss Prevention in the Process Industries. http://dx.doi.org/10.1016/j.jlp.2011.01.008

Roy, B. Vincke, P. (1981). Multi-criteria analysis: survey and new directions. European Journal of Operational Research, 8, 207-18.

Sayadi, MK. Heydari, M., \& Shahanaghi, K. (2009). Extension of VIKOR method for decision making problem with interval numbers. Applied Mathematical Modelling, 33, 2257-2262. http://dx.doi.org/10.1016/j.apm.2008.06.002

Stelios H. Zanakis, Solomon, A. Wishart, N., \& Dublish, S. (1998). Multi-attribute decision making: A simulation comparison of select methods. European Journal of Operational Research, IO7, 507-529. http://dx.doi.org/10.1016/S0377-2217(97)00147-1

Wang, Y.M. Yanga, J.B., \& Xu, D.L. (2005). A preference aggregation method through the estimation of utility intervals. Computers \& Operations Research, 32, 2027-2049. http://dx.doi.org/10.1016/j.cor.2004.01.005

Wu, C.S. Lin, C.T. Lee, C. (2010). Optimal marketing strategy: A decision-making with ANP and TOPSIS. International Journal Production Economics, 127, 190-196. 


\section{Notes}

Note 1. Technique for Order Preference by Similarity to Ideal Solution

Note 2. Elimination and Et Choice Translation Reality

Note 3. Vlse Kriterijumska Optimizacija Kompromisno Resenje

Note 4. Analytic Network Process

Note 5. Preference Ranking Organization Method for Enrichment Evaluations

Note 6. Partially Ordered Set

Table 1. Information of production lines

\begin{tabular}{|c|c|c|c|c|c|c|c|c|c|c|c|c|c|c|}
\hline \multirow{3}{*}{ Бे } & \multicolumn{4}{|c|}{ Maintenance Indicators } & \multicolumn{6}{|c|}{ Product Indicators } & \multicolumn{4}{|c|}{ Quality Indicators } \\
\hline & MTBF & MTTR & $\begin{array}{l}\text { Stoppages } \\
\text { Number }\end{array}$ & $\begin{array}{c}\text { Stoppage } \\
\text { Time }\end{array}$ & Product & Feed & Water & Power & Grinding & $\begin{array}{c}\text { Recovery } \\
\%\end{array}$ & $\mathrm{FE} \%$ & $\mathrm{P} \%$ & FEO \% & \begin{tabular}{|c|} 
Moisture \\
$\%$
\end{tabular} \\
\hline & + & - & - & - & + & - & - & - & - & + & + & - & + & - \\
\hline 1 & 55.24 & 1.06 & 156 & 165.65 & 2142773 & 3038498 & 1211510 & 106189982 & 2403.4 & 69.72 & 67.63 & 0.072 & 16.81 & 9.92 \\
\hline 2 & 55.11 & 1.20 & 156 & 186.6 & 2064221 & 2927036 & 1144013 & 101970768 & 2554.3 & 69.75 & 67.64 & 0.073 & 16.81 & 10.05 \\
\hline 3 & 75.4 & 0.99 & 115 & 113.6 & 2165010 & 3051600 & 1169174 & 107428827 & 2281.6 & 70.16 & 67.59 & 0.075 & 16.72 & 9.81 \\
\hline 4 & 48.82 & 1.37 & 175 & 239.4 & 2109606 & 2996437 & 1231324 & 103643364 & 2298.4 & 69.46 & 67.82 & 0.076 & 17.11 & 10.05 \\
\hline 5 & 82.12 & 0.93 & 96 & 88.97 & 2125810 & 3141474 & 1288555 & 106722957 & 2207.2 & 66.98 & 67.57 & 0.071 & 16.77 & 10.01 \\
\hline 6 & 65.11 & 1.16 & 117 & 135.17 & 2042775 & 3029058 & 1139818 & 102713225 & 1997.5 & 66.38 & 67.55 & 0.071 & 16.66 & 9.89 \\
\hline 7 & 54.53 & 1.58 & 141 & 222.18 & 2052380 & 3018692 & 1191218 & 102155208 & 1942.9 & 67.5 & 67.48 & 0.073 & 16.68 & 9.72 \\
\hline 8 & 60.84 & 0.97 & 129 & 124.65 & 2119625 & 3155746 & 1257265 & 100998239 & 2074.8 & 66.49 & 67.65 & 0.073 & 16.83 & 9.95 \\
\hline
\end{tabular}

Table 2. Weights of indicators

\begin{tabular}{|c|c|c|c|c|c|c|c|}
\hline Indicators & MTBF & MTTR & $\begin{array}{c}\text { Stoppage } \\
\text { Numbers }\end{array}$ & $\begin{array}{c}\text { Stoppage } \\
\text { Times }\end{array}$ & Product & Feed & $\begin{array}{c}\text { Water } \\
\text { consumption }\end{array}$ \\
\hline Weight & 0.074 & 0.035 & 0.032 & 0.021 & 0.211 & 0.071 & 0.038 \\
\hline Indicators & Moisture $\%$ & $\begin{array}{c}\text { Grinding } \\
\text { Media }\end{array}$ & Recovery $\%$ & FE \% & P \% & FEO \% & $\begin{array}{c}\text { Power } \\
\text { Consumption }\end{array}$ \\
\hline Weight & 0.108 & 0.035 & 0.1 & 0.112 & 0.052 & 0.025 & 0.086 \\
\hline
\end{tabular}

Table 3. Result of Ranking

\begin{tabular}{|c|c|c|c|}
\hline \multirow{2}{*}{ RANK } & \multicolumn{3}{|c|}{ METHOD } \\
\cline { 2 - 4 } & TOPSIS & ELECTRE & VIKOR \\
\hline 1 & Line 5 & Line 2 & Line 6 \\
\hline 2 & Line 3 & Line 1 & Line 7 \\
\hline 3 & Line 6 & Line 3 & Line 2 \\
\hline 4 & Line 8 & Line 8 & Line 4 \\
\hline 5 & Line 1 & Line 7 & Line 5 \\
\hline 6 & Line 2 & Line 5 & Line 8 \\
\hline 7 & Line 7 & Line 4 & Line 1 \\
\hline 8 & Line 4 & Line 6 & Line 3 \\
\hline
\end{tabular}

Table 4. Result of Aggregate Methods

\begin{tabular}{|c|c|}
\hline RANK & AGGREGATE \\
\hline 1 & Line 2 \\
\hline 2 & Line 5 \\
\hline 3 & Line 6 \\
\hline 4 & Line 3 \\
\hline 5 & Line 1 \\
\hline 6 & Line 7 \\
\hline 7 & Line 8 \\
\hline 8 & Line 4 \\
\hline
\end{tabular}

